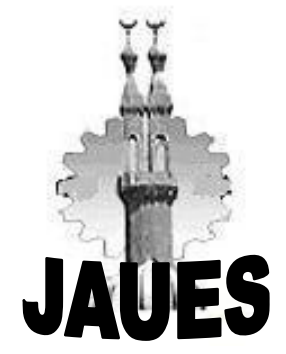

Journal Of Al Azhar University Engineering Sector

Vol. 13, No. 48, July $2018,958-970$

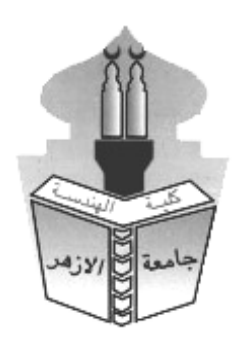

\title{
MICROSTRUCTURE OF A356 AND AA7075 POURED BY COOLING SLOPE CASTING AT DIFFERENT POURING TEMPERATURES.
}

\author{
S. S. Mohamed \\ Mechanical Eng.Department, Shoubra Faculty of Eng. Benha University, Cairo, Egypt.
}

Semisolid metal processing (SSMP) is a technology that involves the formation of metal alloys between solidus and liquidus temperatures. For the step to operate successfully, the microstructure of the starting material consist of solid near-globular grains surrounded by a liquid matrix and a wide solidus-to-liquidus transition area. Thus the process of SSMP relies on the thixotropic behavior of alloys with a spheroidal rather than a dendritic microstructure in semisolid state. Now, this process is industrially successful, generating a variety of products with high quality parts in many industrial sectors. This technology promises advantages over conventional metal forming technologies. Aluminum alloys are among the most prominent and well-known materials used in the mechanical construction and automotive industries. In this investigation, effect of pouring temperature and the type of the materials poured was studied. Molten A356 and AA7075 alloys with temperatures of $620{ }^{\circ} \mathrm{C}, 640{ }^{\circ} \mathrm{C}$ and $660{ }^{\circ} \mathrm{C}$ was poured on the surface of inclined plates then casting in the mould.

\section{KEYWORDS: Cooling slope Casting (CSC), Semi-Solid metal Processing (SSMP), Microstructure of Aluminum Alloys. \\ 1. INTRODUCTION}

Semi-solid processing (SSP) as a modern and advanced technology has been used in the manufacturing of engineering components [1]. Semi-solid metal processing enables us to manufacture complicated shape components with near-net wall, good mechanical properties and high dimension tolerance accuracy [2-4]. SSP has some advantages in comparison with conventional casting, such as decreasing the macrosegregation and solidification shrinkage and reducing forming temperature [5-7]. Because of the absence of the dendritic solid phase in the semi-solid state, the alloy is easily shaped. The nondendritic microstructure contains solid phase globules suspended in the liquid phase [4,8]. Industrial thixocasting of aluminium alloys is based on the benefits in comparison with casting processes, which have led to various serial production methods in spite of the additional costs for primary material and investment costs for heating equipment. However, there is strong competition with highly economical and improved casting processes such as vacuum casting, squeeze casting, fully automated die casting and optimized casting aluminum alloys. [8-11].

\section{EXPERIMENTAL PROCEDURE}

\subsection{FEED STOCK MATERIALS}

In the present work, we used two materials, the first material is A356 commercial hypoeutectic Al-Si cast alloy, and the second material is AA7075 Al-Zn-Cu-Mg high strength wrought aluminum alloy. The chemical composition (by weight percent) is listed in Table 1 and Table 2 respectively.

Table 1 The chemical composition of A356 Al alloy (wt.-\%).

\begin{tabular}{|c|c|c|c|c|c|c|c|}
\hline Alloy & $\mathrm{Si}$ & $\mathrm{Zn}$ & $\mathrm{Mg}$ & $\mathrm{Fe}$ & $\mathrm{Mn}$ & $\mathrm{Ti}$ & $\mathrm{Al}$ \\
\hline A356 & 7.21 & 0.004 & 0.334 & 0.172 & 0.0005 & 0.014 & Bal. \\
\hline
\end{tabular}

Table 2. Chemical composition of AA7075 Al alloy (wt.-\%).

\begin{tabular}{|c|c|c|c|c|c|c|c|c|}
\hline Alloy & $\mathrm{Si}$ & $\mathrm{Zn}$ & $\mathrm{Mg}$ & $\mathrm{Fe}$ & $\mathrm{Cu}$ & $\mathrm{Mn}$ & $\mathrm{Ti}$ & $\mathrm{Al}$ \\
\hline AA7075 & 0.12 & 6.4 & 2.102 & 0.35 & 1.046 & 0.428 & 0.042 & Bal. \\
\hline
\end{tabular}




\subsection{DETERMINATION OF THE SOLIDIFICATION RANGE OF A356 AND AA7075 ALLOY}

The differential scanning calorimetric (DSC) analysis was carried out to determine the solidus and liquidus temperatures for A356 and AA7075 alloys. The DSC experiments were performed using TGDSC16 test apparatus at Central Metallurgical Research and Development Institute (CMRDI), Helwan, Cairo. The DSC experiments were carried during heating with a heating rate of $5{ }^{\circ} \mathrm{C} / \mathrm{min}$. The DSC experiments were carried by using $25 \mathrm{mg}$ of sample from the ingot and heated in helium atmosphere.

\subsection{COOLING SLOPE CASTING (CSC) TECHNIQUE}

Preparation of semi-solid ingot was carried out using cooling slope casting method as follows:-

About $0.8 \mathrm{~kg}$ of each alloy was poured in a graphite crucible and melted in an electric furnace up to 680 ${ }^{\circ} \mathrm{C}$ for superheating. Argon gas was used for degasing to remove any undesirable dissolved gases, and then cooled to the specific pouring temperature. The pouring temperatures $620{ }^{\circ} \mathrm{C}, 640{ }^{\circ} \mathrm{C}$ and $660{ }^{\circ} \mathrm{C}$ were chosen based on the result of the DSC. The pouring temperatures were measured using k-type thermocouple. The molten metal was poured onto the surface of the preheated cooling slope plate with width $90 \mathrm{~mm}$. The slope angle of plate was adjusted at $45^{\circ}$ and the slope length was also fixed at $350 \mathrm{~mm}$, the molten metal was poured immediately on an inclined preheated low carbon steel plate. After the melt was sheared over the surface of the slope plate, it was collected in the preheated mould with a size of 100 $\mathrm{mm}$ diameter and $160 \mathrm{~mm}$ height which has the same material of slope plate. The diameter of the mould was tapered $2^{\circ}$ for easy removal of the feedstock from the mould. Fig. (1) shows schematic representation for the cooling slope casting apparatus, Fig. (2) shows a detailed shape for the mould

(a)

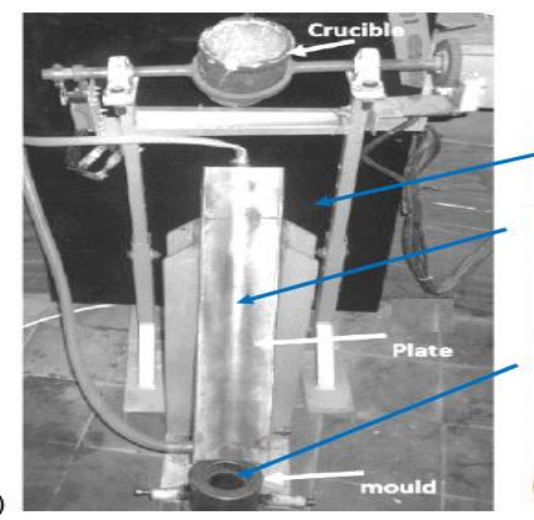

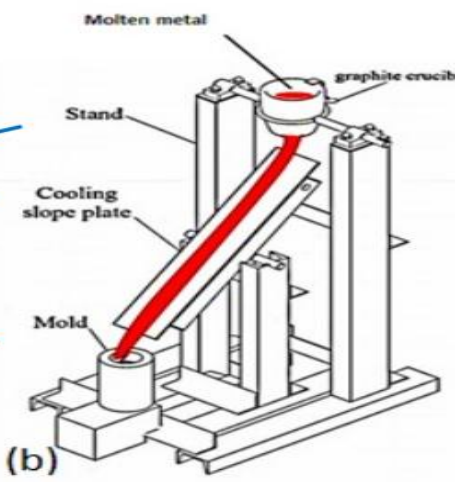

Fig. (1): Cooling slope casting apparatus (a) a photograph of the experimental setup and (b) a schematic illustration

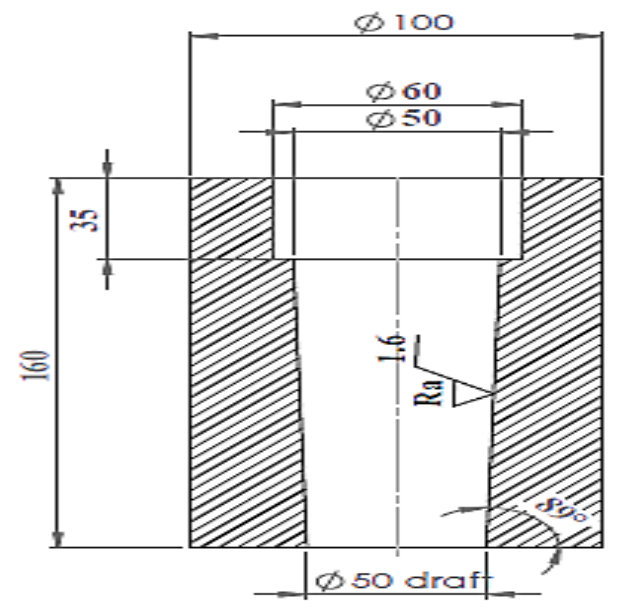

(a)

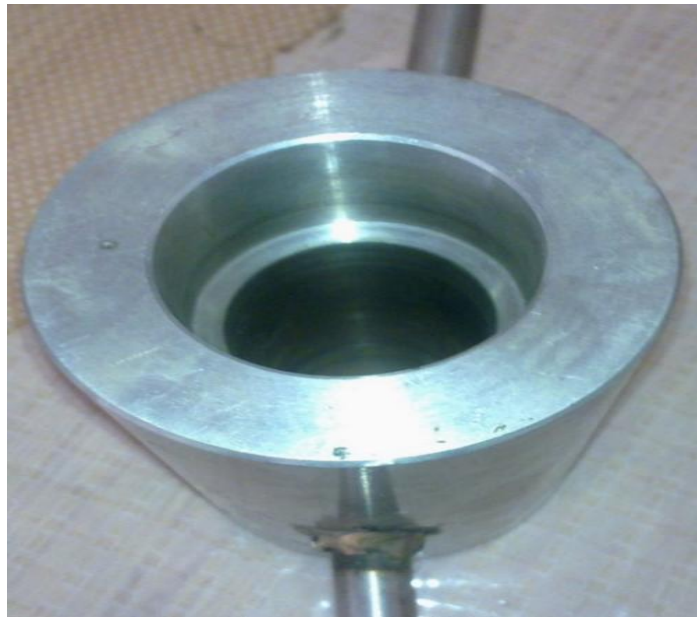

(b)

Fig. (2): (a) A detailed drawing for the mould (dimensions in $\mathrm{mm}$ ), (b) photograph of the mould. 


\subsection{MICROSTRUCTURE PREPARATION}

Figure (3) shows schematic illustration of the feedstock. The top part (open atmospheric riser) with 35 $\mathrm{mm}$ height was removed as it contains the shrinkage cavity. The remained part was cut vertically into two parts, one for macrostructural examination and the other for microstructural examination where three samples were cut from it. The three samples were cut from the top, middle and the bottom of the part as shown. After cutting the samples, they were ground with silicon carbide papers from grit 100 up to 2500 and then polished with alumina using polishing cloth attached on the disk of specimen grinding/polishing machine. The polished surface was etched using a chemical solution consisting of $1 \mathrm{ml}$ of $\mathrm{HF}, 1.5 \mathrm{ml}$ of $\mathrm{HCL}, 2.5 \mathrm{ml}$ of $\mathrm{HNO}_{3}$ and $95 \mathrm{ml}$ of $\mathrm{H}_{2} \mathrm{O}$ for $10-20 \mathrm{~s}$ at ambient temperature (about $25^{\circ} \mathrm{C}$ ). Macroetching was carried out using a chemical solution consists of $5 \mathrm{~g}$. of $\mathrm{NaOH}$ and $100 \mathrm{ml}$ of $\mathrm{H}_{2} \mathrm{O}$ for $5 \mathrm{~s}$ at $\sim 60-70$ ${ }^{\circ} \mathrm{C}$ (warm water). The samples were studied with Olympus optical microscope.

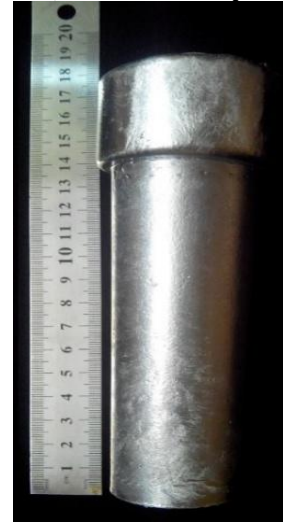

(a)

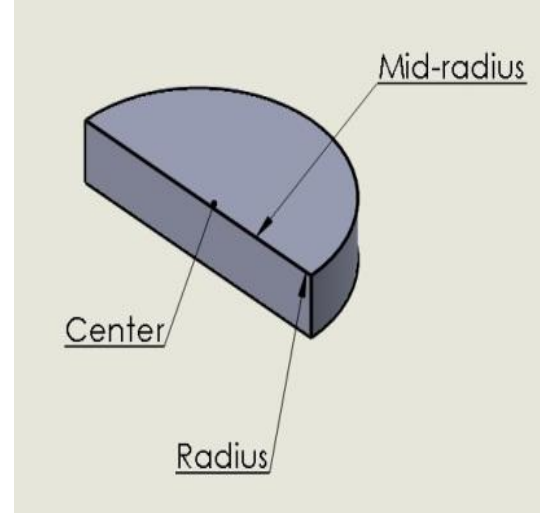

(b)

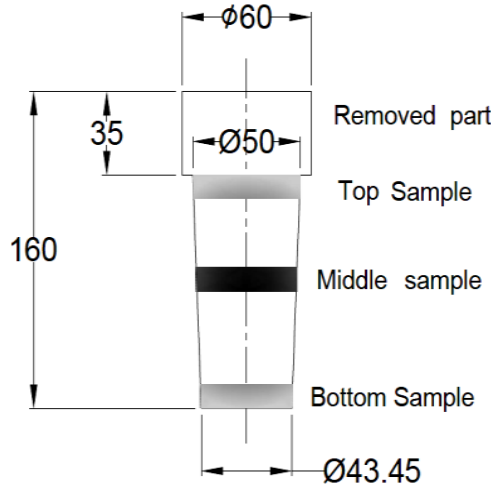

(c)

(3): (a) photographic illustration of the feedstock, (b) Schematic illustration of the sample,(c) Schematic illustra of the feedstock showing the position of metallographic samples.

\subsection{METALLOGRAPHIC EXAMINATIONS}

The microstructural features were analyzed using an image analyzing techniques using JMicroVision software. The size of the $\alpha$-Al primary grains were determined. The average sizes of $\alpha$-Al grains were measured by the linear intercept method.

\subsubsection{Determination of the Size of the Primary $\alpha$-Al Grains}

In the present work, the mean linear intercept method according to the ASTM-E112-9619 was used to calculate the grain size of $\alpha$-Al grains. This method defines the average chord length intersected by the grains on a random straight line in the planar polished and etched section. The mean linear intercept is probably the most widely used measurement method of grain size.

\subsection{DENSITY AND POROSITY MEASUREMENTS}

\subsubsection{Density Measurements}

Density measurements were performed to quantify the volume fraction of porosity in feedstock using three polished specimens (top, center, and bottom) per one sample. The theoretical density of Aluminum alloy is $2.7 \mathrm{~g} / \mathrm{cm}^{3}$. The actual or experimental density $\left(\rho_{\text {exp }}\right)$ was determined in accordance with Archimedes' principle, the specimens were weighed in air and when immersed in distilled water, using the high precision electronic balance, with an accuracy of $\pm 0.005 \mathrm{~g}$.

The actual density was calculated according to Eq. (1):

Where:

$$
\rho_{\text {exp }}=\left[\frac{W_{a}}{W_{a}-W_{w}}\right] \rho_{\text {water }} \quad\left(\mathrm{g} / \mathrm{cm}^{3}\right)
$$

$\rho_{\text {exp }}:$ is the experimental (actual) density $\left(\mathrm{g} / \mathrm{cm}^{3}\right)$.

$\mathrm{W}_{\mathrm{a}}$ : weight of specimen suspended in air $(\mathrm{g})$.

$\mathrm{W}_{\mathrm{w}}$ : weight of specimen suspended in water $(\mathrm{g})$.

$\rho_{\text {water }}$ : density of water $\left(\mathrm{g} / \mathrm{cm}^{3}\right)$. 
Then the relative density can be expressed by the following equation:-

\subsubsection{Porosity Measurements}

$$
\text { Relative density }=\rho_{\exp } / \rho_{t h}
$$

The percentage of porosity content (porosity volume percent) was measured using Archimedes principle. The amount of porosity is determined by the following equation:-

$$
\text { Relative porosity }=1 \text { - relative density }
$$

\section{Results and discussion}

The effect of pouring temperature and type of material on the physical, microstructural of feedstock produced using cooling slope casting (CSC) technique are evaluated and discussed.

\subsection{DETERMINATION OF THE SOLIDIFICATION RANGE OF A356 AND AA7075 ALLOY}

The final result abstained from DSC experiment is the relationship between the heat flow and temperature (HF-T). The variation of the liquid fraction with temperature was calculated from obtained (HF-T) using the methods of partial areas. The calculation procedures carried out to estimate the liquid fraction at any given temperature is illustrated in Fig. (4). According to the Figure, the liquid fraction at any given temperature can be calculated using the following equation [12] and then draw the liquid weight fraction at the same curve.

$$
\% \mathrm{~F}_{\mathrm{L}}(\mathrm{T})=\mathrm{A}_{\mathrm{i}} / \mathrm{A}_{\mathrm{T}}
$$

Where: $F_{L}(T)$ : is the liquid fraction at temperature $T_{i}$.

$A_{i}$ : is the area under HF-T Curve up to the given temperature $T_{i}$.

$\mathrm{A}_{\mathrm{T}}$ : is total area under the HF-T Curve.

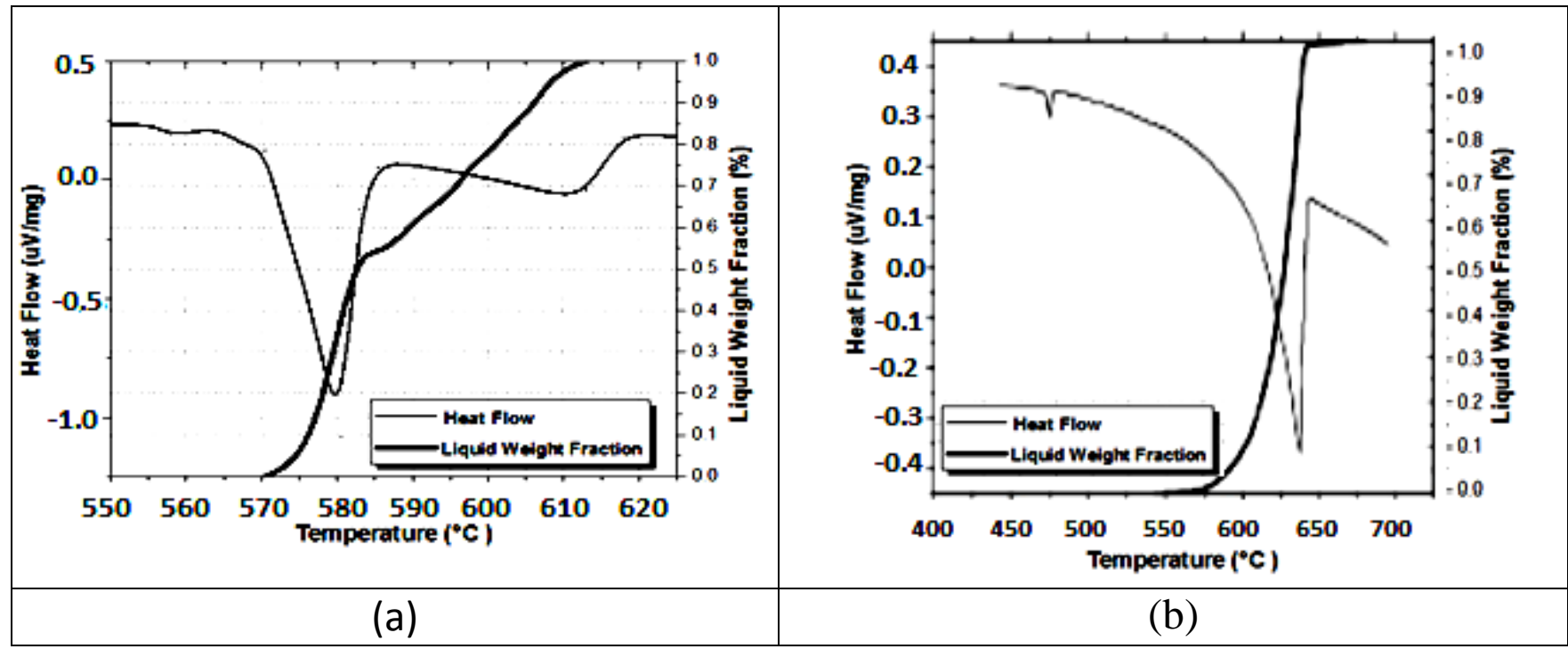

Fig. (4): Heat flow and liquid weight fraction versus temperature

(a) for A356 alloy, (b) for AA7075 alloy.

\subsection{EFFECT OF POURING TEMPERATURES AND TYPE OF MATERIAL ON THE POROSITY}

The porosity of the feedstock produced from the CS casting was measured using water displacement technique (Archimedes principle). Figure (5) shows the variation of porosity of the feedstock with the pouring temperature and the material. It has been found that increasing the pouring temperature increases the bulk porosity for A356 andAA7075. For example, porosity increases from $2.167 \%$ to $3.327 \%$ to $3.808 \%$ when the pouring temperatures are $620^{\circ} \mathrm{C}, 640{ }^{\circ} \mathrm{C}$ and $660{ }^{\circ} \mathrm{C}$, respectively for $\mathrm{A} 356$. 


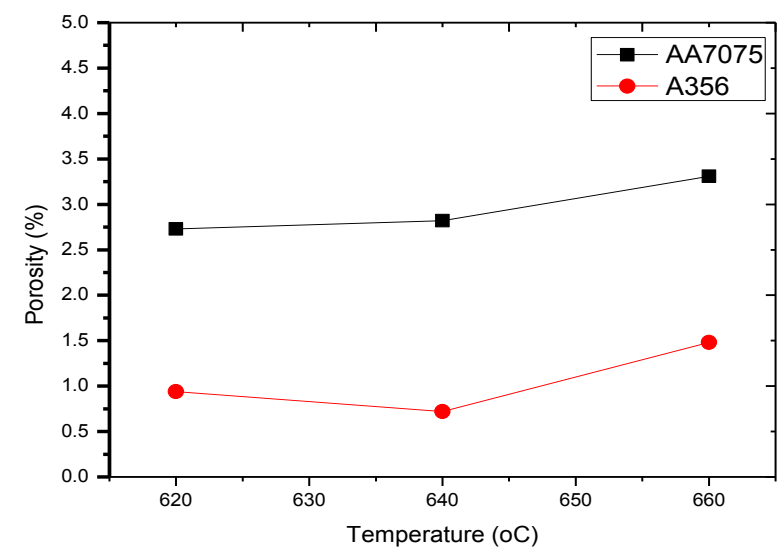

Fig.(5) : The variation of porosity with the pouring temperature for A356 AND AA7075.

From the previous discussion we can conclude that at law superheat and high superheat, the possibility for high bulk porosity content is high. This may be due to that, at law superheat, there is no enough time for air bubbles to escape from die because the molten metal become solid fast. On other hand, at high superheat the ability of gas dissolving from environment is high. Therefore, we can say that the best pouring temperature is the medium superheat $\left(640^{\circ} \mathrm{C}\right)$ because this pouring temperature gives the gas entrapped the enough time to escape from die and decrease the ability of gas dissolving in the die. Also, we find that the porosity for AA7075 is higher than the porosity of A356. This result due to the liquid weight fraction at the same temperature for A356 is higher than the liquid weight fraction for AA7075, that allow the air bubbles to escape from A356 easier than AA7075.

\subsection{MICROSTRUCTURAL EXAMINATIONS}

The microstructure of the as-received A356 cast aluminum alloy has dendritic structure that consists mainly of dendritic primary $\alpha$ - $\mathrm{Al}$ grains (white regions) and coarse $\mathrm{Al}-\mathrm{Si}$ eutectic structure.

Figures (6) to (11) show optical micrographs for the microstructure of the A356 and AA7075 feedstock poured at various pouring temperature. The microstructures are obtained at 100X magnification for all the samples and were taken at axial and radial locations. The micrographs show nearly spherical, rosette shaped grains and finer eutectic silicon particles, where the dendrite breaking is caused by the shear stress due to the slope of the flow. The radius zone exhibited the finest primary $\alpha$-Al grains when compared with the center and mid-radius of the feedstock, because of large heat dissipated from the molten metal through the mould. The micrographs show also $\alpha$-Al grains for AA7075 is smaller than $\alpha$-Al grains for

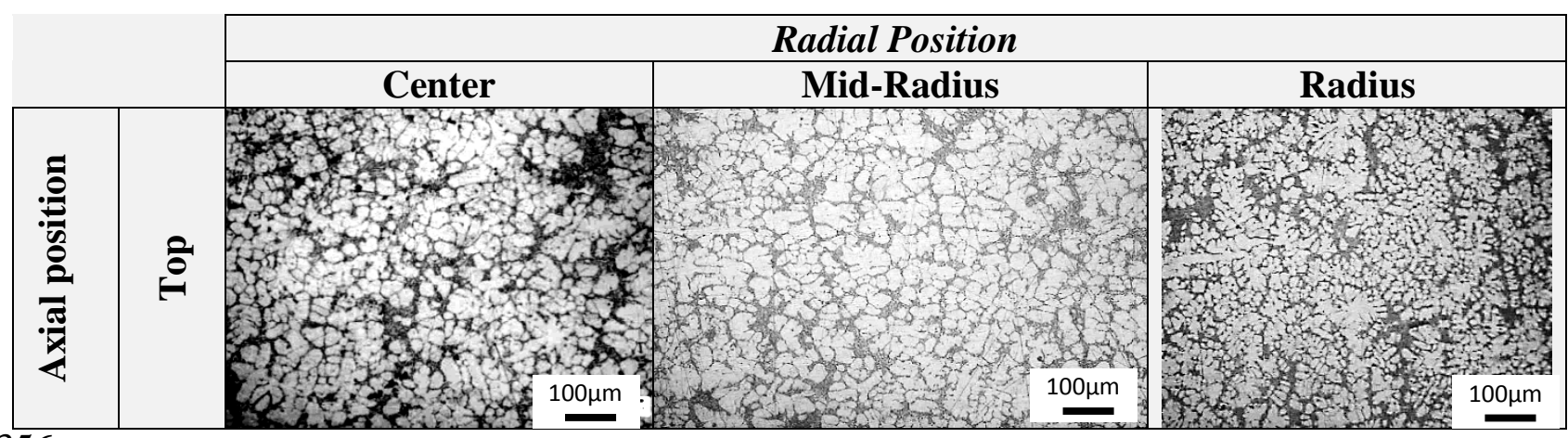

A356. 
MICROSTRUCTURE OF A356 AND AA7075 POURED BY COOLING SLOPE CASTING AT DIFFERENT POURING TEMPERATURES.

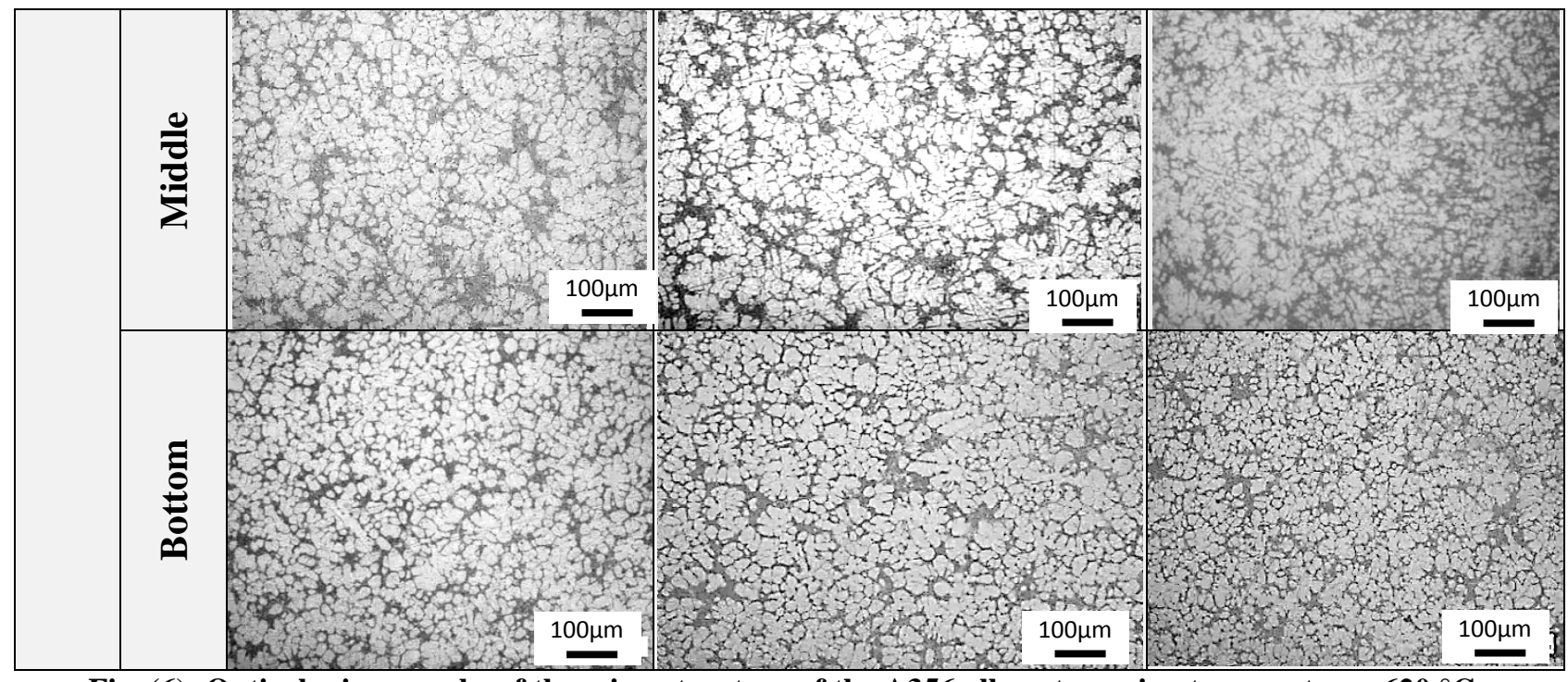

Fig. (6): Optical micrographs of the microstructure of the $\mathrm{A356}$ alloy at pouring temperatures $620{ }^{\circ} \mathrm{C}$.

Fig. (7): Optical micrographs of the microstructure of the $\mathrm{A356}$ alloy at pouring temperatures $640{ }^{\circ} \mathrm{C}$.

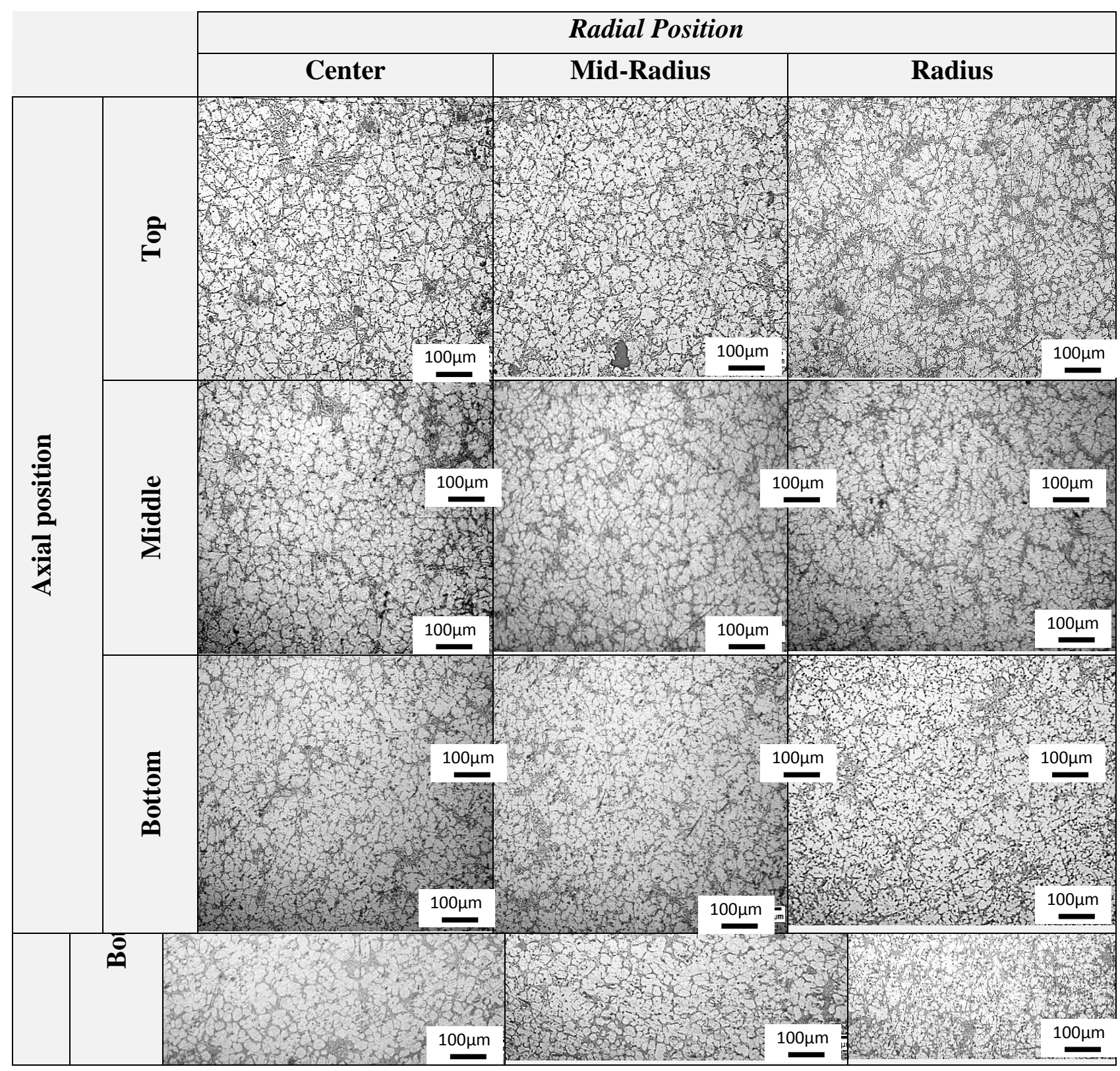


MICROSTRUCTURE OF A356 AND AA7075 POURED BY COOLING SLOPE CASTING AT DIFFERENT POURING TEMPERATURES.

Fig. (8): Optical micrographs of the microstructure of the A356 alloy at pouring temperatures $660{ }^{\circ} \mathrm{C}$.

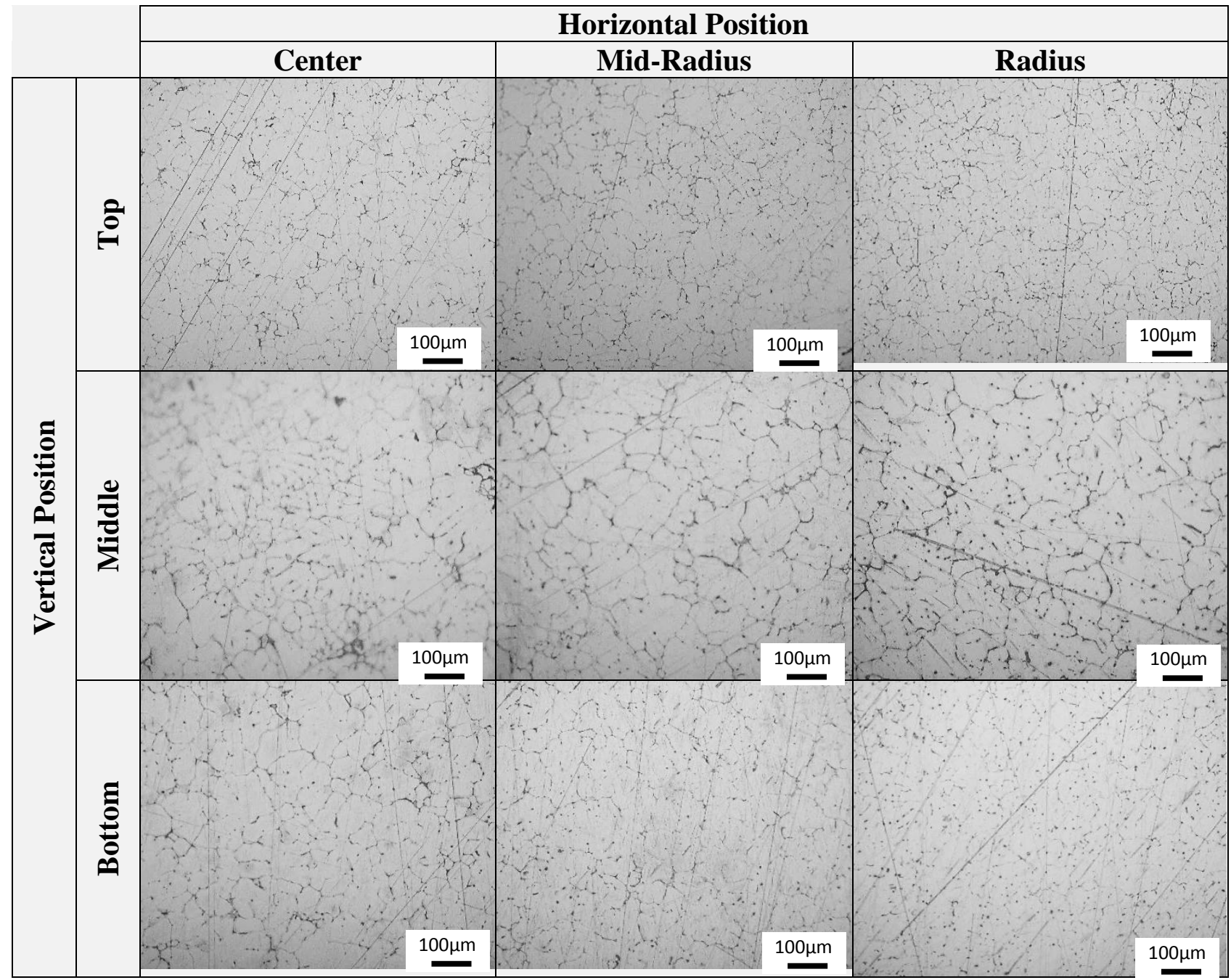

Fig.(9). Optical micrographs of the microstructure of the AA7075 alloy at pouring temperatures $620^{\circ} \mathrm{C}$.

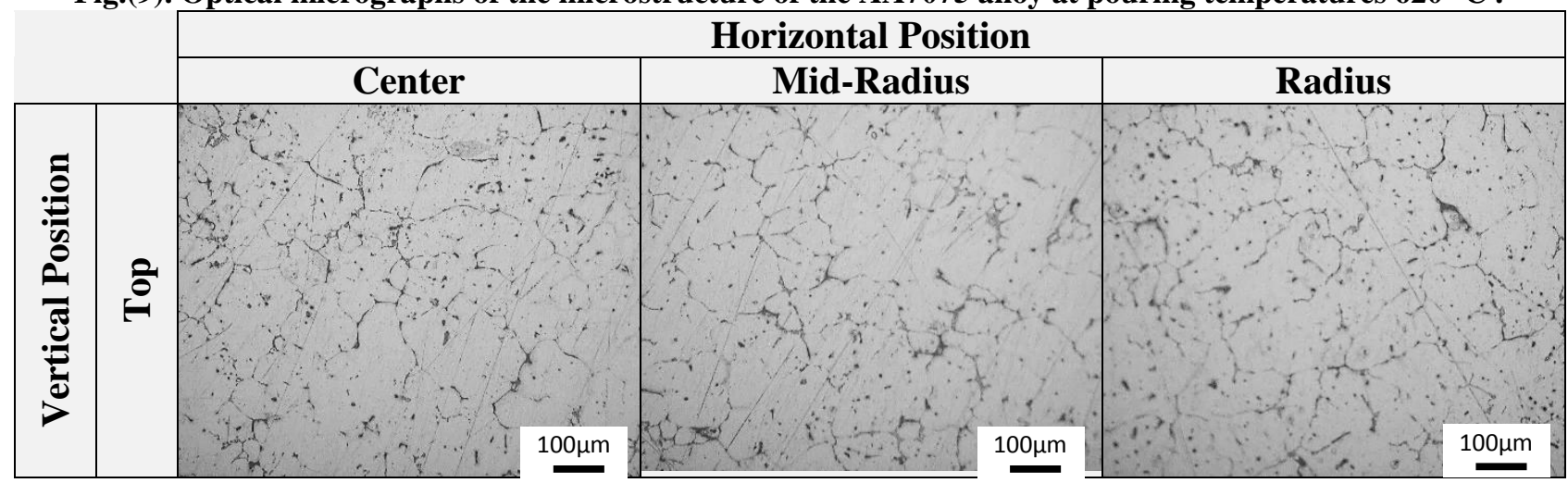


MICROSTRUCTURE OF A356 AND AA7075 POURED BY COOLING SLOPE CASTING AT DIFFERENT POURING TEMPERATURES.
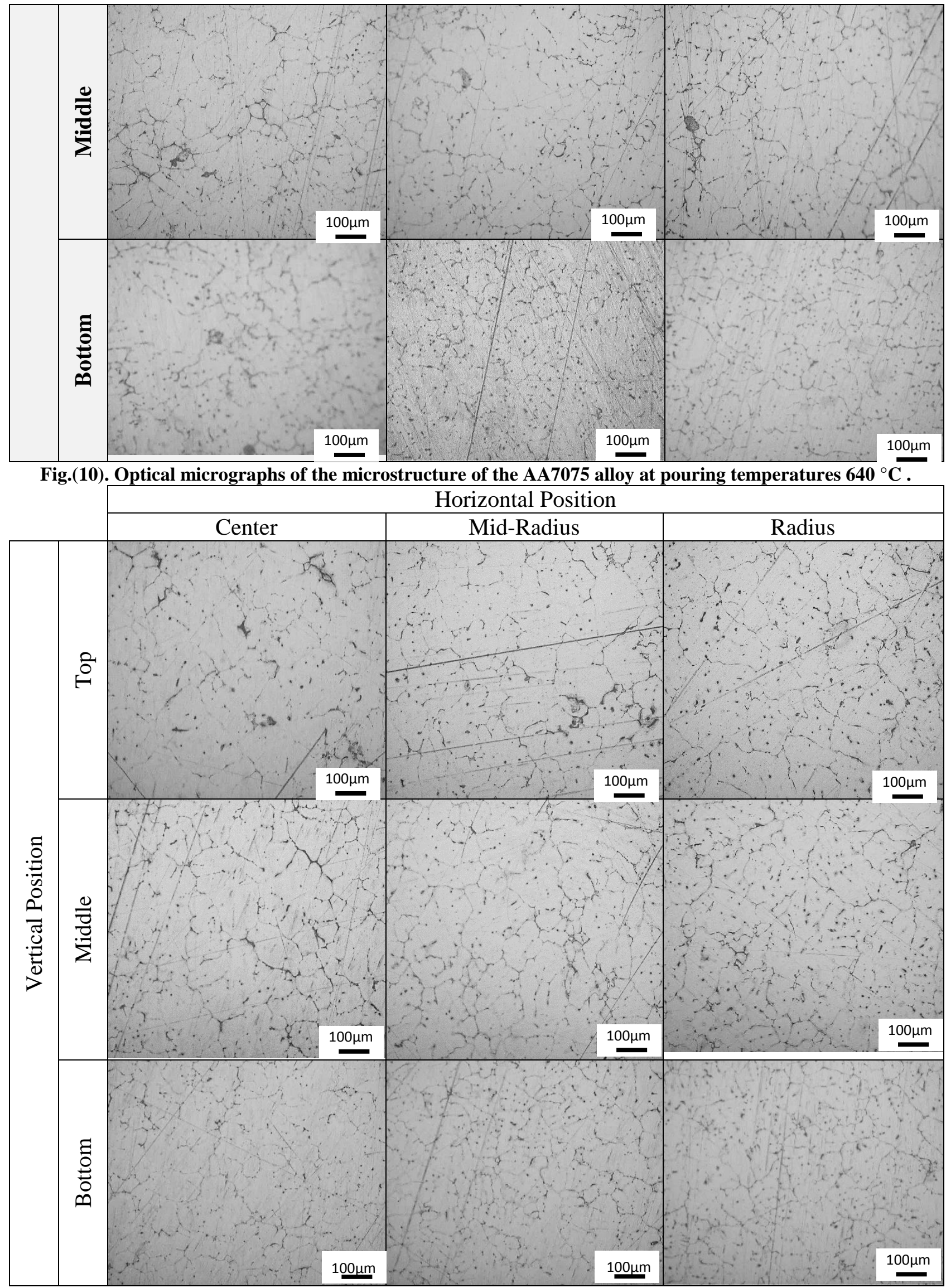

Fig.(11). Optical micrographs of the microstructure of the AA7075 alloy at pouring temperatures $660^{\circ} \mathrm{C}$ 
Table (3): Values of the grain size in $(\mu \mathrm{m})$ of the primary $\alpha$-Al grains at axial and radial locations of the A356 C S Cast ingot poured at different pouring temperature.

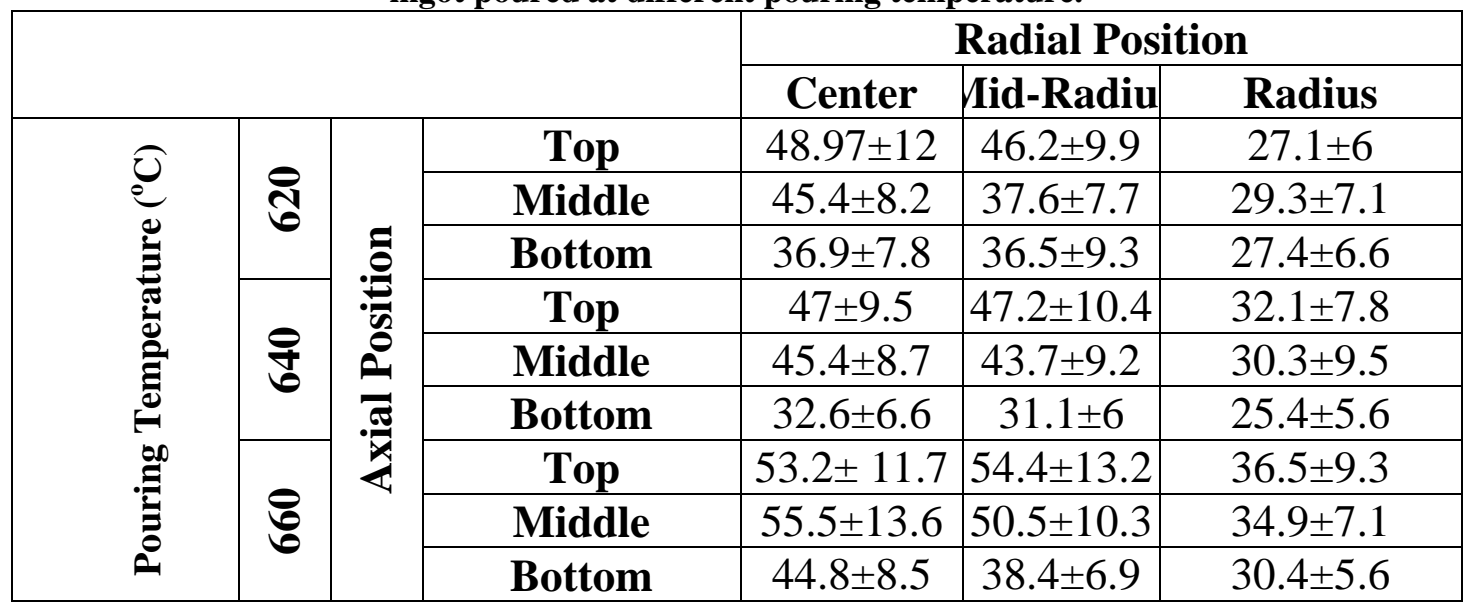

Table (4): Values of the grains size in $(\mu \mathrm{m})$ of the primary $\alpha$-Al grains at axial and radial locations of the AA7075 CS cast ingots poured at different pouring temperature.

\begin{tabular}{|c|c|c|c|c|c|c|}
\hline & \multicolumn{3}{|c|}{ Radial Position } \\
\hline & & & & Center & Mid-Radius & Radius \\
\hline \multirow{9}{*}{ 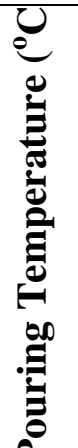 } & \multirow{3}{*}{ గ్రి } & \multirow{8}{*}{ 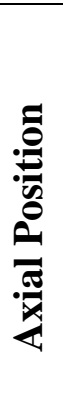 } & Top & $34.00 \pm 10.40$ & $37.55 \pm 11.95$ & $39.46 \pm 12.61$ \\
\hline & & & Middle & $37.15 \pm 11.62$ & $35.12 \pm 12.00$ & $34.21 \pm 10.28$ \\
\hline & & & Bottom & $32.00 \pm 9.46$ & $37.00 \pm 12.01$ & $37.00 \pm 10.00$ \\
\hline & \multirow{3}{*}{ 早 } & & Top & $33.30 \pm 12.15$ & $43.80+11.40$ & $35.75 \pm 12.11$ \\
\hline & & & Middle & $30.98 \pm 10.57$ & $36.14 \pm 12.15$ & $34.68 \pm 11.70$ \\
\hline & & & Bottom & $23.26+8.26$ & $23.51+7.79$ & $22.60 \pm 10.28$ \\
\hline & \multirow{3}{*}{8} & & Top & $56.36 \pm 18.68$ & $54.74 \pm 16.38$ & $55.00 \pm 15.51$ \\
\hline & & & Middle & $50.13 \pm 14.96$ & $53.22 \pm 15.89$ & $53.64 \pm 15.36$ \\
\hline & & & Bottom & $49.50 \pm 12.26$ & $49.29+11.94$ & $54.54 \pm 14.52$ \\
\hline
\end{tabular}

Tables $(3,4)$ list the values of the grain sizes of A356 and AA7075 of the primary $\alpha$-Al grains at axial and radial locations of the A356 and AA7075 feedstock produced by various pouring temperatures. Generally, the feedstock exhibited lower average grain size at the bottom of feedstock when compared with the middle and the top of the feedstock. For example, for the feedstock poured at $620{ }^{\circ} \mathrm{C}$ for A356 ,the average grain size of $\alpha$-Al grains at top, middle and bottom positions of the feedstock were, $48.97 \mu \mathrm{m}$, $45.4 \mu \mathrm{m}$ and $36.9 \mu \mathrm{m}$, respectively. It has been also found, at radial position of the feedstock, that the primary $\alpha$ - Al grains have generally lower grain size near the radius (surface) positions of feedstock than the mid-radius and center positions of the feedstock. By increasing temperature from $620{ }^{\circ} \mathrm{C}$ to $640{ }^{\circ} \mathrm{C}$, at bottom position, the average grain size of A356 changes from $36.9 \mu \mathrm{m}$ to $32.6 \mu \mathrm{m}$ at center, from 36.5 $\mu \mathrm{m}$ to $31.1 \mu \mathrm{m}$, at mid-radius, and from $27.4 \mu \mathrm{m}$ to $25.4 \mu \mathrm{m}$ at radius position.

For AA7075 by increasing temperature from $620{ }^{\circ} \mathrm{C}$ to $640{ }^{\circ} \mathrm{C}$, at bottom position, the average grain size changes from $32.00 \mu \mathrm{m}$ to $23.26 \mu \mathrm{m}$ at center, from $37.00 \mu \mathrm{m}$ to $23.51 \mu \mathrm{m}$, at mid-radius, and from 37.00 $\mu \mathrm{m}$ to $22.6 \mu \mathrm{m}$ at radius position. By increasing pouring temperature from $640{ }^{\circ} \mathrm{C}$ to $660{ }^{\circ} \mathrm{C}$ the average grain size begins to increase again. The average grain size increases to $49.50 \mu \mathrm{m}$ at center zone, to 49.29 $\mu \mathrm{m}$ at mid-radius zone, and to $54.54 \mu \mathrm{m}$ at radius zone. 
MICROSTRUCTURE OF A356 AND AA7075 POURED BY COOLING SLOPE CASTING AT DIFFERENT POURING TEMPERATURES.
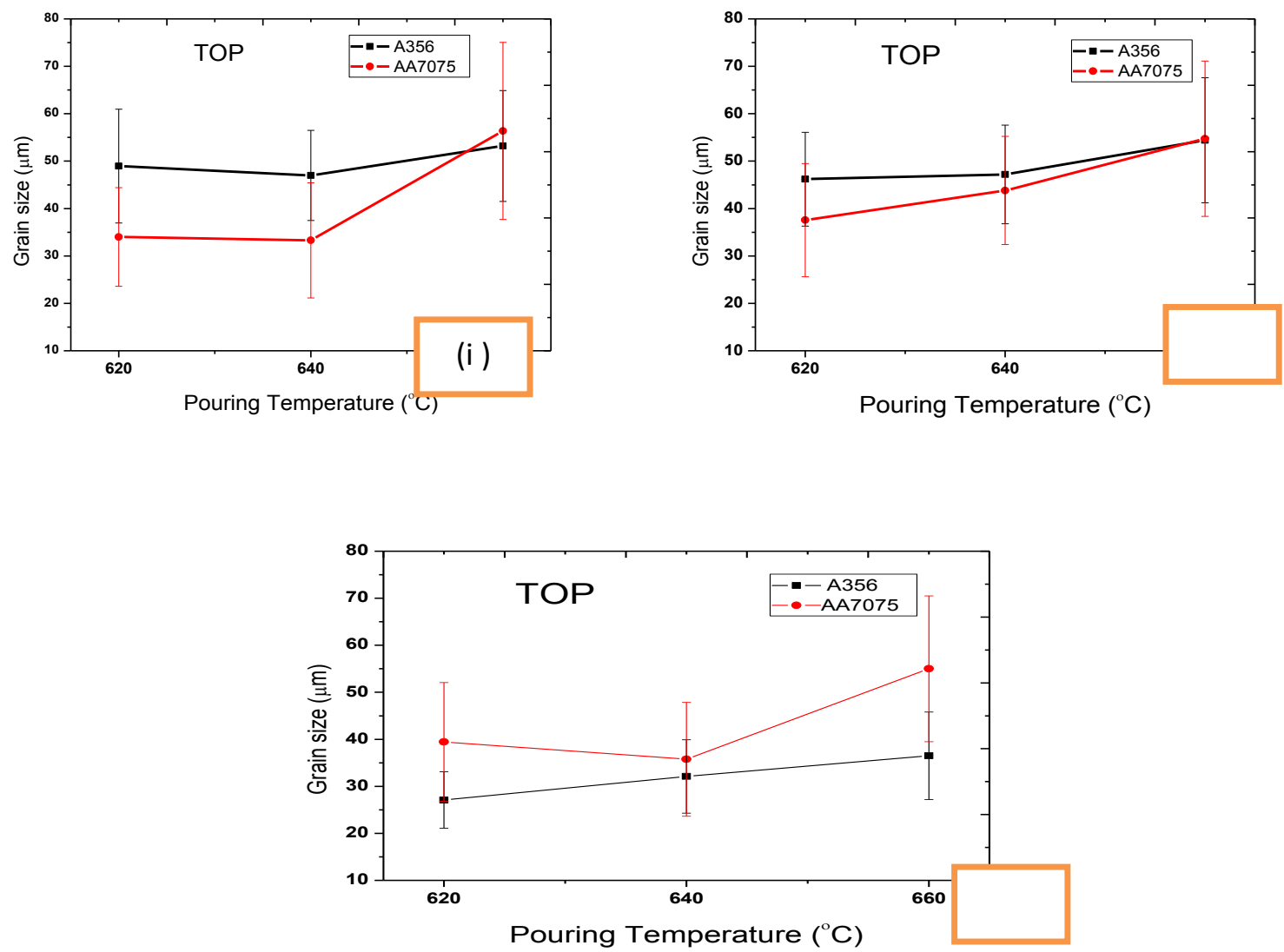

Fig. (12- a) The variation of the average grain size of the primary $\alpha$-Al grain at TOP for A356 and AA7075 at: (i) Center, (ii) Mid-Radius, and (iii) Radius.
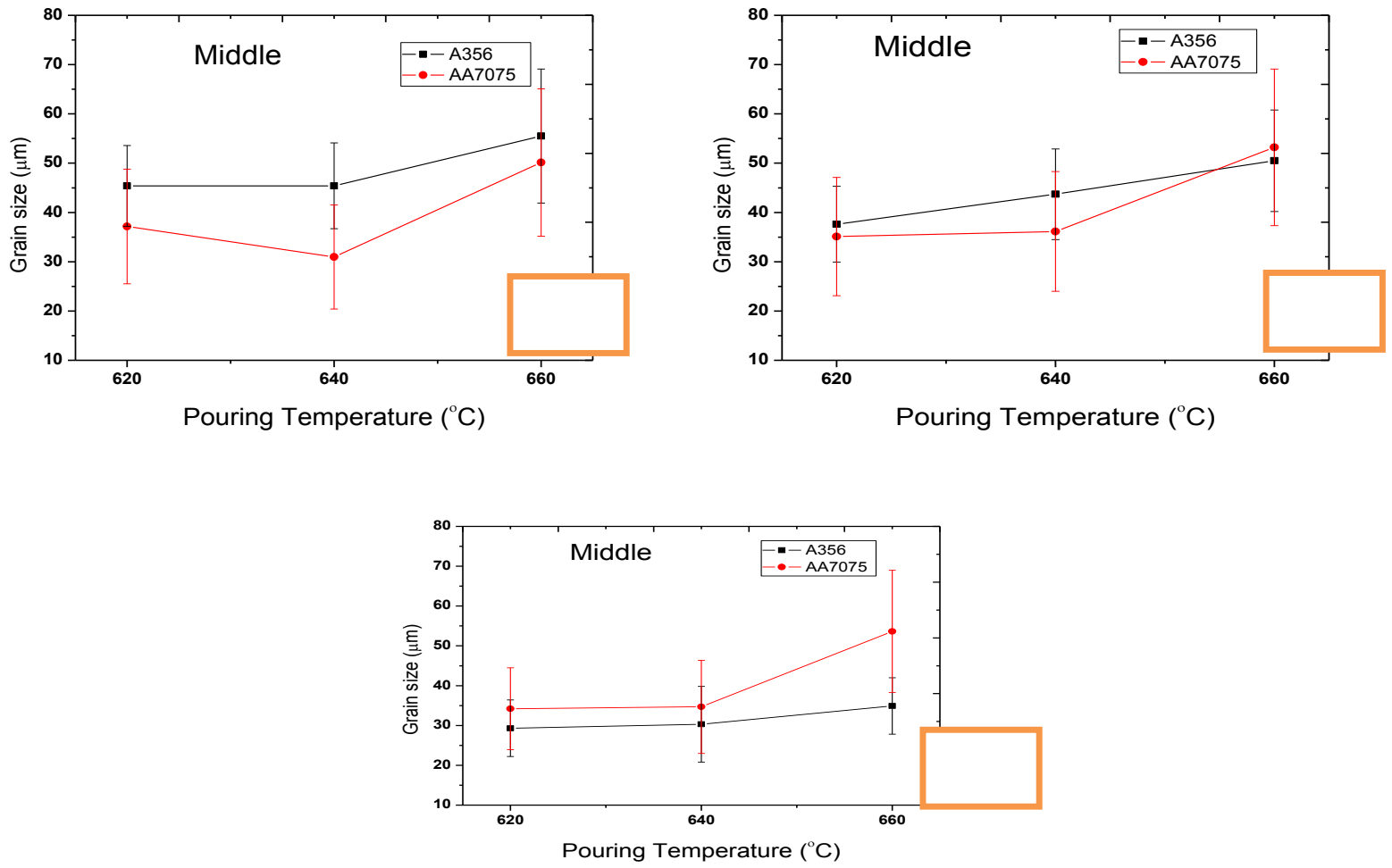

Fig. (12- b) The variation of the average grain size of the primary $\alpha$-Al grain at Middle for A356 and AA7075 at: (i) Center, (ii) Mid-Radius, and (iii) Radius. 

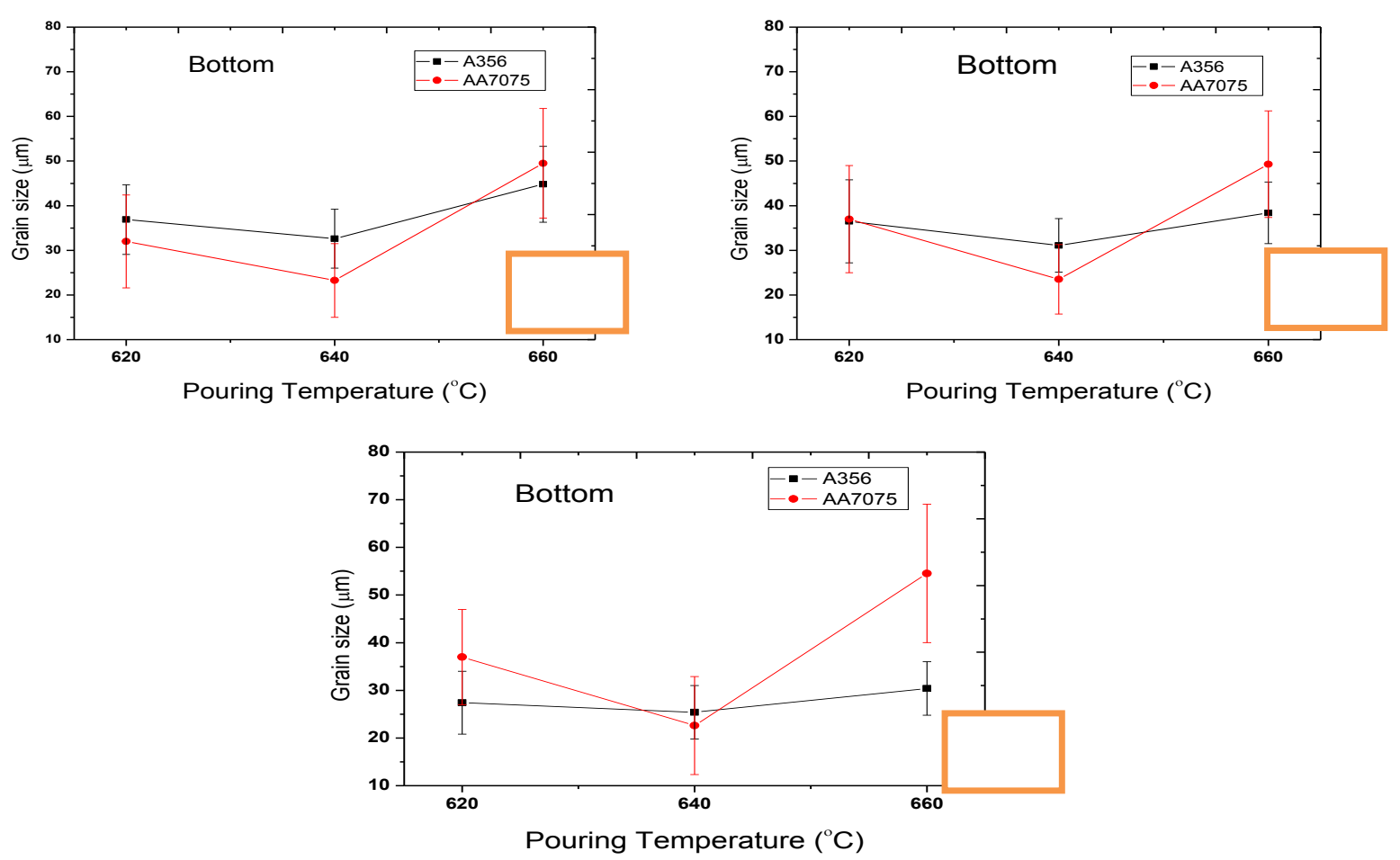

Fig. (12- C) The variation of the average grain size of the primary a-Al grain at Bottom for A356 and AA7075 at: (i) Center, (ii) Mid-Radius, and (iii) Radius

Figure $(12-a, b, c)$ shows the variation of the average grain size of the primary $\alpha$-Al grains at axial and radial locations of the A356 and AA7075. The high pouring temperature leads to decrease in nucleation, remitting the primary crystals and undesired grain growth. The low pouring temperature causes rapid solidification of melt on the slope and thus dendritic solidification. It is cleared from Figure 12 that the minimum grain size for AA7075 is obtained at $640^{\circ} \mathrm{C}$.

\section{CONCLUSIONS}

The study in this research has discussed the application of Cooling Slope casting process for the generation of semi-solid feedstock of A356 and AA7075 alloys by changing the pouring temperatures, the following conclusions can be drawn:

1. The porosity of the poured material affected by pouring temperature. The porosity provides less value at $640^{\circ} \mathrm{C}$.

2. The porosity of A356 less than porosity of AA7075 at the same poured temperature.

3 . The size and morphology of primary $\alpha$-Al phase were affected by the pouring temperatures. The grain size increased with increasing the pouring temperature.

4. The primary $\alpha-\mathrm{Al}$ size for AA7075 less than primary $\alpha$-Al size for A356.

5. A356 and AA7075 feedstock poured at a pouring temperature of $640{ }^{\circ} \mathrm{C}$ exhibited best microstructural characteristics.

\section{REFERENCES}

1. Shuiian Cheng and et al., "Effect of Process Parameters on the Microstructure of Semi-solid ZL101 Aluminum Alloy" Mat. Res. vol.19 no.3 São Carlos May./June 2016 Epub Apr 08, (2016).

2. S. Gencalp and N. Saklakoglu, "Semisolid Microstructure Evolution during Cooling Slope Casting under Vibration of A380 Aluminum Alloy”, Materials and Manufacturing Processes, 25:9, pp. 943947(2010).

3. Kaio Niitsu Campo, and et al., "Influence of the processing route on the microstructure of aluminumalloyA356 for thixoforming." Materials Characterization. 85, pp. 26-37 (2013).

4. I.S.El-Mahallawi, and et al., "Effect of pouring temperature and water cooling on the thixotropic semi-solid microstructure ofA319 aluminium cast alloy." Materials Research, 18(1), pp.170-176 (2015).

5. Yucel Birol, "A357 thixoforming feedstock produced by cooling slope casting." Journal of Materials Processing Technology, 186(1.3), 94.101 (2007). 
6. S.Chayong, and et al., "Thixoforming 7075 aluminium alloys." Materials Science and Engineering A, 390, PP.3-12 (2005).

7. K.S. Alhawari, and et al., "Evaluation of the microstructure and dry sliding wear behaviour of thixoformed A319 aluminum alloy", Materials \& Design, pp. 169-180. (2015).

8. Q.D. Qin, and et al., "Semisolid microstructure of $\mathrm{Mg}_{2} \mathrm{Si} / \mathrm{Al}$ composite by cooling slope cast and its evolution during partial remitting process", Materials Science and Engineering, A444 (1-2), pp.99103(2007).

9. S.B. Hassas-Irani, and et al., "Microstructure evolution and semi-solid deformation behavior of an A356 aluminum alloy processed by strain induced melt activated method", Materials \& Design, 46, pp. 579-587(2013).

10. N. Haghdadi, and et al. "The semisolid microstructural evolution of a severely deformed A356 aluminum alloy", Materials \& Design 49, pp. 878-887, (2013).

11. M.N.Mohammed, and et al. "Semi-solid metal processing techniques for non-dendritic feedstock production", The Scientific World Journal. Article ID 752175, 16 pages. doi:10.1155/2013/752175 (2013).

12. S.Wang, F. Cao, R.Guan, and J.Wen, "Formation and evolution of non-dendritic microstructures of semi-solid alloys prepared by shearing/cooling roll process," Journal of Materials Science and Technology, vol. 22, no. 2, pp. 195-199(2006). 